APRESENTAÇÃO 


\section{UNA MEMORIA PUESTA EN ESCENA}

Para su número 12, la revista Caracol ha apostado por un monográfico (dossiê) dedicado al trauma y su memoria. Fenómenos como la dictadura, la guerra o el terrorismo arrastran, desde la perspectiva del presente, un pasado fuertemente conflictivo, traumático, que permanece sin resolver hasta que esas memorias son atendidas. Esta atención puede proporcionarse desde la esfera individual, en un tratamiento de aspectos más emocionales, o desde la esfera colectiva, a través de iniciativas de corte político. A todas estas opciones hace alusión el concepto de Vergangenheitsbewältigung ("superación del pasado"), término que describe los procesos desplegados en la Alemania contemporánea para enfrentarse a su pasado traumático y a la memoria del Holocausto. Las políticas llevadas a cabo por las instituciones alemanas han permitido una asimilación del trauma y una normalización de esa memoria traumática en la sociedad, en la esfera colectiva. A ello contribuyen también iniciativas de corte más individual que se incardinan, fundamentalmente, en el ámbito de la cultura: la tematización artística, literaria y teatral de esa memoria se ha entendido como una herramienta más para afrontar el pasado, asumir la memoria y superar el trauma.

Tanto España como América Latina han padecido eventos traumáticos y viven en la contradicción de gestionar esa memoria para poder mirar sin complejos al futuro. Mientras que Argentina consiguió aprobar la nulidad de las leyes de Obediencia Debida y Punto Final, en España el juez Baltasar Garzón, responsable de la detención de Augusto Pinochet, fue suspendido cautelarmente en sus funciones por pretender investigar los crímenes del Franquismo. Estas disparidades hablan de una memoria que en los mejores 
casos está siendo digerida y, en los peores, aún no ha comenzado a serlo. La producción cultural, sin embargo, va por delante de la legislación y le propone a la sociedad una serie de productos artísticos, literarios y teatrales de gran valor para que esa digestión pueda, al menos, llevarse a cabo en la esfera individual.

En el ámbito de la investigación académica abundan los estudios sobre el modo en que géneros como la novela o el cine articulan esas memorias traumáticas. Sin embargo, el teatro ha sido en buena medida pasado por alto en este panorama. Este monográfico de Caracol se concentra de manera exclusiva en el teatro y en el modo en que este género posibilita la articulación de la memoria y la superación del trauma desde su especificidad escénica. De este modo, este número nace de la necesidad de llenar un hueco en la investigación: prestando atención a los tratamientos teatrales de la memoria traumática, por un lado, y poniendo el foco en el mundo hispanohablante, por otro.

El número se abre con el artículo de Aimaretti "Una ruina habitada desde el presente: vestigios del horror, la resistencia y el duelo. A propósito de La Ilíada de Teatro de los Andes (2000)". El hecho de que el monográfico arranque con este trabajo es deliberado: el caso boliviano no es paradigmático en los estudios de memoria del ámbito hispano, donde otros países como Argentina, Chile o España suelen copar la atención investigadora. De este modo, desde Caracol se ha buscado concederle al dossiê una entrada no canónica que desliza el foco hacia latitudes hasta ahora pasadas por alto. En este artículo la autora se centra en el análisis de un espectáculo de teatro político que gira en torno a la violencia y la impunidad y que, en este sentido, 
aborda desde su carácter performativo tanto la violencia y el dolor como la resistencia y el (derecho al) duelo. Teatro de los Andes, el grupo teatral sobre el que trabaja Aimaretti, alcanzó con este y otros montajes visibilidad internacional especialmente en el contexto latinoamericano, ya que su propuesta parte de Bolivia pero su interpretación trasciende las fronteras y habla del drama de los países de la región. La Ilíada propuso una relectura del pasado reciente para poner de manifiesto el negacionismo, las políticas de olvido y la invisibilización de las víctimas en América Latina: a través de la repetición del horror, el montaje plantea la necesidad de aprender del dolor para cuestionar el presente. Lo interesante de esta propuesta escénica es que, además, parte de un texto clásico, La Ilíada, para hacer una lectura en clave contemporánea que retoma el texto desde un contexto boliviano para incidir en la pervivencia inquebrantable del horror y la violencia en la región.

El artículo de Zalba, “¿Memoria u Olvido?: Negociando la identidad presente con los fantasmas del pasado en Té de tías de Cristina Escofet”, nos adentra en la Argentina de la dictadura militar. La autora aborda en su estudio un texto, Té de tías, en que un agresor y su víctima se enfrentan a los fantasmas de sus antecesores. Mientras la muchacha violada sale adelante al asumir, a través de un proceso de melancolía, el dolor y la memoria del trauma, reconociendo y dando espacio a sus fantasmas, el hombre poderoso, el agresor, intenta restaurar el pasado a través de un proceso de nostalgia que no únicamente no le salva, sino que le conduce a la muerte, ya que su amnesia selectiva le induce a repetir errores del pasado. Esta lectura es de gran interés en tanto que pone en evidencia las dos actitudes ante el pasado vigentes en 1985, año de la obra, poco tiempo después del final de la dic- 
tadura militar: la confrontación con el pasado y la asunción de la memoria llevan a la reconciliación y al descanso, mientras que el tratamiento selectivo y parcial de ese mismo pasado es garantía de una condena segura.

El monográfico avanza con el capítulo de Perera, "De mujeres, pícaros y fugas: memorias de la guerra de Malvinas", que ahonda en la situación de Argentina a través de otro aspecto traumático y, sin embargo, profundamente ligado a la dictadura: la guerra de las Malvinas. El trabajo se centra en el estudio de Piedras dentro de la piedra, texto teatral estrenado en 2012 que vuelve, treinta años después, sobre el conflicto. El tema de las Malvinas reviste, de hecho, un especial interés para la articulación de la memoria en Argentina no sólo por la guerra en sí, sino por lo que ese conflicto tuvo de emblemático para la dictadura y su construcción de un relato incuestionable. Así, a la desmalvinización del discurso de la post-dictadura le siguió una nueva malvinización en el periodo 2003-2015, época de las políticas de Memoria, Verdad y Justicia, en que la guerra reapareció resignificada en torno a un nuevo discurso anti-imperialista que cuestionaba el relato de la dictadura. Perera analiza, desde este marco, los personajes femeninos en la guerra fuera del eje víctima/héroe y los describe en base a patrones femeninos no subyugados, consiguiendo sustraerlos de los pilares del discurso de la dictadura: la guerra y la nación.

El artículo de Costa y Rojo, "Visibilidad de la violencia en el teatro actual latinoamericano: El año en que nací, de Lola Arias, La mujer puerca y Mau Mau, o la tercera parte de la noche, de Santiago Loza", aborda dos autores argentinos contemporáneos que proponen distintas formas de enunciación y de articulación de la memoria. Por un lado se estudian dos textos, en su re- 
lación con la puesta en escena, de Santiago Loza, cuya dramaturgia personal cuestiona principios y normas de las sociedades latinoamericanas al tiempo que aborda la etapa de la dictadura argentina. Por otro lado, la obra de Lola Arias, centrada en la dictadura chilena, es sometida a una interpretación en clave puramente escénica: desde la fase de creación colectiva del espectáculo a través de una serie de performers no profesionales que reconstruyen sus infancias, desdibujando los límites entre realidad y ficción, hasta el uso de objetos reales ("índices de memoria") que, a través de la desacralización de los archivos y los documentos de la época de Pinochet, articulan una memoria performativa del trauma.

La segunda parte del monográfico se concentra en el teatro espańol, si bien no en textos que aborden memorias traumáticas de la propia Espańa, sino de otros lugares, incidiendo así en una caracterización desensimismada y cosmopolita de la escena espańola contemporánea. El primer trabajo de este bloque es el de Luz C. Souto, "Escenarios cruzados. El trauma argentino en el teatro español: Si un día me olvidaras de Raúl Hernández Garrido". Este artículo, como su propio título sugiere, continúa con la memoria de la dictadura argentina pero abordándola desde una perspectiva ajena: la española. Para la autora es relevante el hecho de que desde España, que ha sufrido también una guerra y una dictadura, se tematice la memoria traumática argentina ya que, en efecto, esta mirada exterior no sólo contribuye a sumar perspectivas, sino que además señala la necesidad de una memoria transatlántica, que en la actualidad está ganando peso en el discurso académico. Así, Souto aborda la dramaturgia de la masacre a través del texto $\mathrm{Si}$ un día me olvidaras, en que se da cuerpo a tres de los grandes traumas del 
pasado reciente argentino: los vuelos de la muerte, los centros clandestinos de detención y torturas y la apropiación de menores.

El siguiente capítulo es “Pesan los muertos de ayer y de mañana’. El conflicto árabe-israelí en el teatro español actual”, de Paola Bellomi. La autora comienza su trabajo con unas reflexiones sobre Max Aub, uno de los pocos autores en lengua española que ha abordado sin ambages la cuestión judía, para intentar dar respuesta, a continuación, a la siguiente pregunta: ¿por qué es tan escasa la producción teatral sobre el conflicto palestino-israelí en España? Bellomi hace girar su argumentación en torno a las ideas de que se trata de un conflicto por un lado ajeno y, por otro, indeleblemente vinculado a la expulsión de los sefardíes e incluso a la política pro-Hitler de Franco. Tras hacer un repaso por el breve corpus de obras con esa temática, la autora destaca cómo otros aspectos como el drama de los refugiados gozan de una mayor presencia en la escena española actual y hace un balance crítico muy certero de este panorama.

A continuación, el artículo de Manuel Aznar, "La recepción crítica del estreno de Himmelweg, de Juan Mayorga, en Madrid", aborda uno de los textos teatrales que Bellomi ya mencionaba en su artículo: Himmelweg. La obra, estrenada en 2003, da forma escénica a la memoria del Holocausto a través de un episodio concreto: la visita de un Delegado de la Cruz Roja al campo de Theresienstadt, en que un comandante nazi orquesta una representación teatral que esconde el horror al que están sometidos los presos. Así, después de su visita, el Delegado escribe un informe positivo sobre lo que ha visto. Himmelweg es una de las obras más icónicas de Juan Mayorga, que es, a su vez, el dramaturgo español más celebrado en la actualidad, 
tanto en España como fuera de ella. En este trabajo, Aznar se hace eco de la recepción en prensa tanto de la obra como de su puesta en escena y recoge las opiniones, fuertemente dispares, que ambas suscitaron entre los críticos de la prensa madrileña.

Al hilo de este artículo, la entrevista de Berta Muñoz Cáliz al dramaturgo Juan Mayorga cierra el dossiê de este número de Caracol. Se trata de una conversación de la investigadora con el autor, que nos revela su visión sobre el Holocausto, que para él "no es solo un acontecimiento extraordinario; de algún modo es el acontecimiento". Esta afirmación incide, en efecto, en el hecho de que, como muestra este monográfico, la memoria de eventos ajenos a la propia historia de España sea central en la escena española contemporánea. Partiendo de esta premisa, el autor explica cómo este evento traumático le interpela constantemente y cómo su memoria "puede fortalecer nuestra sensibilidad, nuestro esqueleto moral, en el tiempo que nos toca vivir”. Las acertadas preguntas de la entrevistadora conducen al autor a brillantes reflexiones sobre el derecho a la ficcionalización de eventos traumáticos y sobre los límites de la representación que, a su vez, le permiten tomar una clara posición sobre el uso del pasado no como herramienta ideológica sino como manera de suscitar una emoción de compasión por el ser humano. Estas reflexiones, que inciden en la necesidad de seguir haciendo memoria desde la escena, le brindan un broche de lujo a este monográfico.

De este modo, el número 12 de Caracol nos ofrece una selección de trabajos que incluye reflexiones sobre el teatro entendido como texto y como puesta en escena, pero también como práctica cultural sujeta a fenómenos extrateatrales como, por ejemplo, la crítica. A partir de esta noción polié- 
drica de teatro, los trabajos que componen el dossiê reflexionan sobre cómo estas expresiones teatrales articulan memorias traumáticas del pasado tanto en América Latina como en España, y tanto de asuntos propios como de eventos traumáticos del calibre del Holocausto. Así, este número monográfico viene a situar el debate sobre la memoria en el ámbito teatral, con el ánimo de despertar nuevos intereses y suscitar nuevos espacios de reflexión y diálogo.

Diego Santos Sánchez

Universidad de Alcalá. 